\title{
Developments in GPR Based NDT for Ballastless Track of High-Speed Railways
}

\author{
Xiaoting XIAO ${ }^{\mathrm{a}, 1}$, Guiyun TIAN ${ }^{\mathrm{b}}$, Dong LIU ${ }^{\mathrm{a}}$, Mark ROBINSON ${ }^{\mathrm{b}}$ and Anthony \\ GALLAGHER ${ }^{\mathrm{b}}$ \\ ${ }^{a}$ School of Automation Engineering, University of Electronic Science and Technology \\ of China \\ ${ }^{\mathrm{b}}$ School of Engineering, Newcastle University, UK
}

\begin{abstract}
For the past decades, ballastless track has been developed and used successfully throughout the world. Due to the multi-layer concrete structure of a ballastless track, timely detection of problems becomes a significant challenge. Ground Penetrating Radar (GPR), as an effective nondestructive method, has been applied to ballastless track in the last ten years. This paper reviews the state-of-theart of GPR for the ballastless track. The challenges and problems are highlighted and discussed. A Vector Network Analyser (VNA) based stepped-frequency GPR system is considered for the problems and detection requirements. The experimental results show that the proposed system can detect narrow cracks in the depth up to $50 \mathrm{~cm}$.
\end{abstract}

Keywords. Ballastless track, high-speed railway, ground penetrating radar, nondestructive testing, Vector Network Analyser (VNA)

\section{Introduction}

Railways currently in service can be divided into two categories: ballast and ballastless [1]. The latter is also known as slab track [2]. With the rapid development of the highspeed railway, ballastless track has been widely used. The high-speed railway construction mileage of China is expected to reach 39,000 kilometers by the end of 2020 [3]. The advantages of ballastless track include the improvement in smoothness, stability, and safety; reduction of structure height and maintenance, etc. [4-5]. The disadvantages are the requirement for very high stability for the subgrade and higher construction costs. Different problems, such as inner cracks and interlayer gaps, may occur due to the construction quality, subgrade sinking, drastic weather changes, etc. However, as a ballastless track is composed of a multi-layer concrete structure, timely detection of problems and planning of maintenance is a significant challenge for ballastless railways [6].

The common inspection methods for ballast track such as digging trenches and taking core samples are not applicable for ballastless track, since they are expensive, destructive, time-consuming [7] and have low spatial sampling density. Ground Penetrating Radar (GPR), a commonly used non-destructive testing (NDT) equipment, has a great potential in ballastless track inspection since it is efficient and effective for

\footnotetext{
1 Corresponding Author Xiaoting Xiao, E-mail: xt_xiao@foxmail.com.
} 
both qualitative and quantitative evaluations of different defects [8]. In this paper, we focus on the applications of GPR for defects of ballastless track. A newly developed stepped-frequency GPR system is presented with some promising experimental results.

\section{Review of Ground Penetrating Radar}

For ballastless track, there is less research on inspection methods than for ballast track. However, we can refer to the successful use of GPR on traditional ballast track and other concrete structures.

\subsection{Basic principles of GPR}

Radar systems can be divided into two types: pulse and continuous wave $(\mathrm{CW})$. Pulse GPR systems either transmit very short impulses (on the order of nanoseconds) or longer pulses (such as linear FM chirps) where pulse compression is employed when the received data is processed. Impulse GPR is the most used as it is relatively easy to implement and requires minimal processing to obtain useful data. However, the penetration depth is limited by the required resolution.

Continuous-Wave $(\mathrm{CW})$ systems are less common and require more complex transceiver circuitry. To obtain ranging information the wave is FM modulated, either continuously (FMCW: Frequency-modulated continuous wave) or discretely (SFCW: Stepped-frequency continuous wave). The radial resolution of FMCW and SFCW systems is dependent on their frequency discrimination capabilities, whereas for pulse systems it is dependent on the full width at half maximum (FWHM) of the transmitted waveform or the result of a matched filter applied to the transmitted waveform.

Regardless of the modulation technique used, RF energy is injected into the subsurface by the transmitting antenna and collected by the receiving antenna, which is usually collocated. For pulsed systems, the received signal is amplified by a variable gain amplifier and then digitized by an ADC. For CW systems the output of the variable gain amplifier is input to a mixer where it is multiplied by the signal from the transmitter, and the lower frequency output is digitized by the ADC. Each pulse or modulation period produces a one-dimensional graph, known as an A-scan. As the radar moves over the surface, numerous collected A-scans are then used to form a two-dimensional image or B-scan, as illustrated in Figure 1.

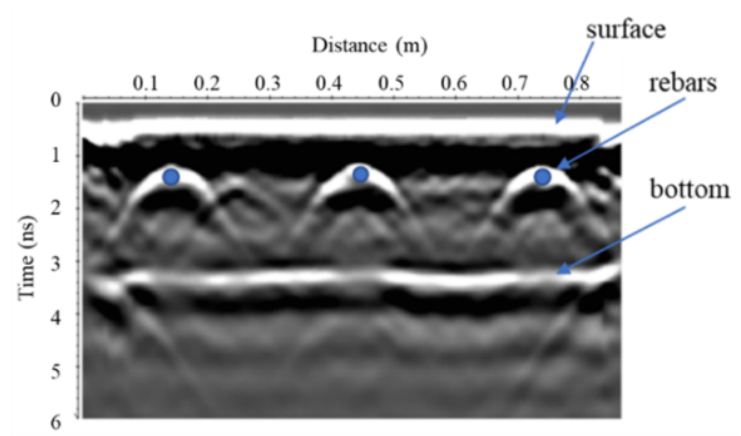

Figure 1. An example of pulse GPR detection B-scan on a concrete slab [9] 
The hyperbolas seen in Figure 1 are due to the diffractions of the rebars. It can be observed that point sources appear as hyperbolas, because of the range between the antennas and the target changes while the radar is in motion. Reflections are due to differences in dielectric permittivity in the subsurface. A portion of the energy in the incident wave reflects from the object, and the remainder refracts through discontinuities, the respective amounts being determined by the ratio of refractive indices as indicated by the Fresnel equations. When the incident angle is zero (normal incidence on the ground surface),

$$
R=\left|\frac{n_{1}-n_{2}}{n_{1}+n_{2}}\right|^{2}, T=1-R,
$$

where $R$ and $T$ are the fractions of the incident power that are reflected and transmitted, respectively. For air-coupled systems, signals enter the receiver from three sources: 1) a direct wave from the transmitter through free space, 2) a wave reflecting from the ground surface and above ground clutter sources, 3) waves reflecting from discontinuities in the subsurface.

The vertical axis of the B-scan is the two-way travel time $t_{w t}$, typically given in nanoseconds, which is converted to depth (time-depth conversion) using

$$
d=\frac{c t_{w t}}{2 \sqrt{\varepsilon_{r}^{\prime}}}
$$

where $t_{w t}$ is in seconds, $c$ is the velocity of light in vacuum and $\varepsilon^{\prime}{ }_{r}$ is the real part of the relative permittivity (dielectric constant) of the subsurface medium.

\subsection{Types of GPR systems}

Currently, most of the commercial systems are pulse radar systems except for the stepped-frequency GPR from 3D-Radar ${ }^{\circledR}$. The widespread of pulse radar systems is mainly due to their easiness of use and data interpretation. These systems can also be divided into two categories according to the configuration: cart-mounted system and vehicle-mounted system. The cart-mounted systems are the traditional systems that are pushed by operators. They are widely used in the field of civil engineering, hydrology, mining, archeology, geology, etc. [10]. The antennas can be either ground-coupled or air-coupled in different circumstances. The vehicle-mounted systems can be much more efficient and useful in the inspections of the road [11], tunnel [12], ballast railway [6], etc. In this configuration, the antennas are required to be air-coupled.

\section{Ballastless Railways}

Several types of ballastless track have been developed in different countries, which all use concrete in place of ballast. As a result, a ballastless track faces the same durability problems as concrete, such as the effects of temperature, freezing and thawing, corrosion of reinforcing elements, carbonation, cracks, etc. [13-14].

In China, the ballastless track types used in high-speed railways are listed as follows [15-16]:

- Using pre-cast slabs, CRTS I-III (CRTS: China railway track system);

- With cast in situ slabs, twin-block and sleeper buried ballastless track. 
Most of the ballastless tracks in Chinese high-speed railways use pre-cast slabs. Current NDT inspections also focus on these types of ballastless tracks. A typical structure is shown in Figure 2, consisting of the support plate, CA mortar layer, track slab, fastener, and rail.

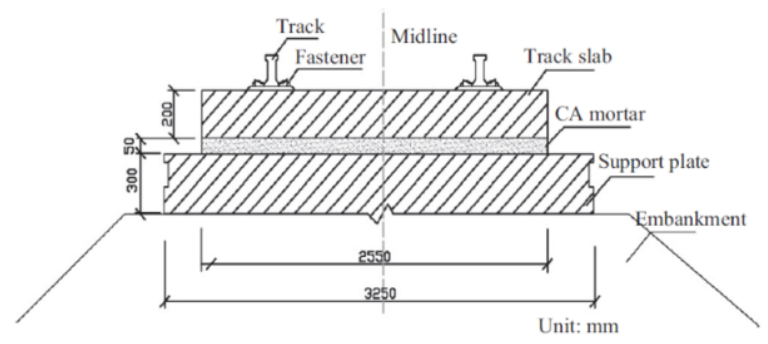

Figure 2. Transverse section of ballastless track [16]

\subsection{Common defects of ballastless railways}

With the construction and operation of high-speed railways, Chinese Railways found that many defects in ballastless track may affect the operational safety and durability of the railways, summarized in Table 1 [6]. What can be observed from this table is that many factors can cause different degrees of damage to a ballastless track. Therefore, it is necessary to carry out line inspection and maintenance frequently to eliminate potential security risks. More time and expertise must be devoted to the non-destructive detection of faults in the future, especially in China. Currently, NDT methods for defect detection of ballastless track include Ultrasonic methods [17], Impact echo [18], GPR [19], etc. GPR is considered the best NDT method for ballastless track since it is effective for both qualitative and quantitative evaluations of different defects at the same time.

Table 1. Main defects and causes of ballastless railways

\begin{tabular}{lll}
\hline \multicolumn{1}{c}{ Defect types } & \multicolumn{1}{c}{ Causes } & \multicolumn{1}{c}{ Consequences } \\
\hline Track slab cracks & $\begin{array}{l}\text { Insufficient reinforcement, } \\
\text { construction quality, etc. }\end{array}$ & Lateral separation cracks \\
$\begin{array}{l}\text { CA mortar defects, } \\
\text { interlayer gaps }\end{array}$ & $\begin{array}{l}\text { Dry-wet cycles, temperature } \\
\text { gradient, concrete under or over } \\
\text { tamping, etc. }\end{array}$ & $\begin{array}{l}\text { Heavier gaps and vertical cracks, } \\
\text { precipitation accumulates in the gaps }\end{array}$ \\
$\begin{array}{l}\text { Support layer cracks and } \\
\text { deformation } \\
\text { Voids inside the layer }\end{array}$ & $\begin{array}{l}\text { Subgrade uneven settlement } \\
\text { Uneven tamping, foreign } \\
\text { matter doping, etc. }\end{array}$ & $\begin{array}{l}\text { Increment of tensile stress of track slab, } \\
\text { shortened service life } \\
\text { Breakdown of track slab or support plate }\end{array}$ \\
\hline
\end{tabular}

\subsection{GPR inspections and challenges}

The capability of GPR to detect defects in ballastless track or concrete slabs has been validated by many studies. Researchers in Germany [18-19] found it to be practical to combine several NDT methods, such as impact-echo, ultrasonic echo, and GPR, for the inspection of ballastless track. Li [20] applied GPR to the detection of interlayer gaps and produced effective results in evaluating the grouting effect. The use of low frequencies for ballastless track is limited due to the presence of rebars in track slabs 
[17], results in limited penetration depth Moreover, although the vehicle-mounted GPR has been widely used in the inspection of ballast track [7,21], the GPR systems for ballastless track are usually hand-towed with the antennas ground-coupled to the surface of the trackbed.

From the above, some challenges and problems remain for the inspection of ballastless track using GPR. Firstly, GPR detection cannot be as accurate as other NDT methods in some circumstances, such as for distinguishing weak bonding and no bonding points. Secondly, existing research focuses on the use of the pulse GPR system, with which the penetration depth is limited by the required resolution. Thirdly, the system is usually hand-towed with the ground-coupled antennas. Despite the configuration, properly planned detection lines and suitable processing algorithms are necessary [22].

\section{Newly developed GPR for ballastless track}

To improve the signal resolution and testing efficiency of GPR systems, a radar system using SFCW signals was developed in this work. The SFCW system integrates a pair of air-coupled antennas, making it possible to be adapted to an integrated vehicle-mounted system for damage detection and safety assessment of high-speed railways in the future.

The developed SFCW system is shown in Figure 3. The horn antennas are used as the bi-static configuration for transmitting and receiving radar signals. Data are collected by sweeping frequency in the range of $1 \mathrm{GHz}-4 \mathrm{GHz}$. The idea of using SFCW for a GPR system is not new. It has already been applied to the detections of concrete, limestone, pavement, etc. [23-25]. Several advantages of the system facilitate the detection of high-speed railways, such as: 1) SFCW uses low-cost (low speed, low power) equipments compared to that of pulse GPR; 2) obtained information is richer as it contains magnitude and phase in frequency domain; 3) better resolution with wider operating bandwidth [26]. Moreover, the SFCW system is capable of the Quantitative Non-Destructive Evaluation (QNDE) of railway structural layers and other concrete structures $[23,27]$.

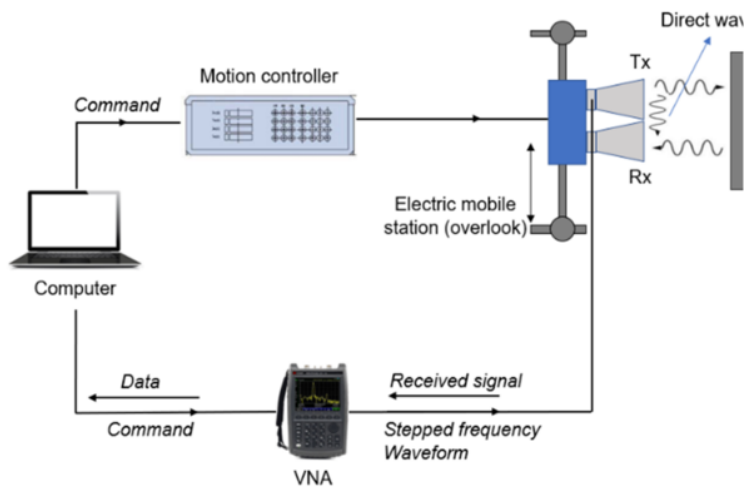

(a)

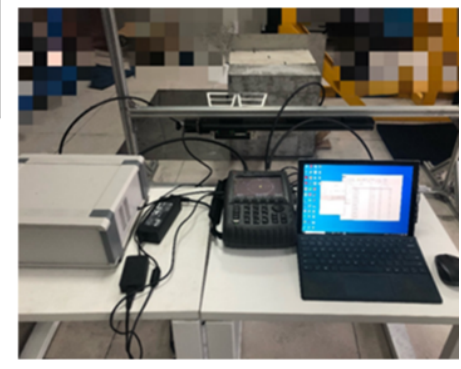

(b)

Figure 3. Schematic diagram (a) and photograph (b) of the SFCW system 


\subsection{Working principals of SFCW radar}

The basic principles of SFCW radar systems are similar to FMCW except that the frequency changes in discrete steps rather than continuously. The step waveform is generated digitally and then converted to an analog signal that is high pass filtered and then drives a voltage-controlled oscillator (VCO). This results in the stepped frequency waveform $f_{1}(t)$ with an angular velocity of $\omega_{0}+(\Delta \omega) N$, where $\omega_{0}$ is the initial angular velocity, $\Delta \omega$ is the discrete angular frequency increment and $N$ is the step number. The signal is then split into the transmitted signal (which is amplified and fed into the transmitting antenna) and $f_{2}(t)$ that is input to a mixer in the receiver segment.

The received signal is amplified and fed into a mixer. The amplified received signal $f_{3}(t)$ is mixed with $f_{2}(t)$ and the result is low pass filtered to yield the intermediate angular frequency $\omega_{3}-\omega_{2}$. This signal is then digitized, which gives the frequency domain response.

\subsection{Signal processing}

The Vector Network Analyzer (VNA) based GPR system relies on the S parameters of the VNA to obtain the frequency response of the detected system. For the bi-static antenna configuration, the return loss $S_{21}(f)$ is collected. After analyzing the response, the characteristic information of the detection target is finally obtained. The following diagram illustrates the methodology we employ to acquire the time domain wave field from the raw data.

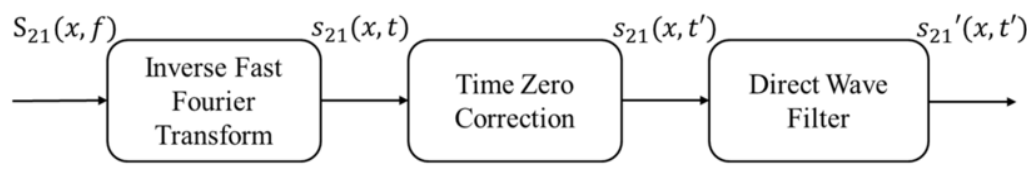

Figure 4. Block diagram of the signal processing procedure

First, the Inverse Fast Fourier Transform (IFFT) is used to transform the system response from the frequency domain $S_{21}(x, f)$ to the time domain $s_{21}(x, t)$. For digitized $N$ points signal $S_{21}(N)$ in the frequency domain, the inverse discrete Fourier transform (IDFT) formula can be given by

$$
S_{21}(n)=\frac{1}{N} \sum_{k=0}^{N-1} S_{21 k} e^{i 2 \pi k n / N} \quad n=0, \ldots, N-1
$$

where $s_{21}(n)$ is the discrete signal in the time domain, plotting an A-scan at one scanning step. The set of A-scans forms a 2D B-scan image, with respect to the distance and the propagation time. Second, the distance between the centers of the two antennas is measured to be $d=16.5 \mathrm{~cm}$. The propagation time of the direct wave from the transmitter to the receiver is calculated by $t_{0}=d / c=0.55 \mathrm{~ns}$, where $c=3 \times 10^{8} \mathrm{~m} / \mathrm{s}$ is the wave's velocity in the air. So, the true time zero of the B-scan should be $0.55 \mathrm{~ns}$ before the arrival of the direct wave. Last, the direct wave is filtered using a rectangular window to improve the image quality of the IFFT data.

\subsection{Laboratory measurement}

An experimental setup was designed in the lab, as shown in Figure 5(a). Concrete2 
represents the concrete sample of track slab, fabricated with the C50 concrete (based on China's national standard GB50010-2010), with a dimension of $20 \times 50 \times 50 \mathrm{~cm}^{3}$. Concrete 3 represents the sample of the support plate, fabricated with $\mathrm{C} 15$ concrete, with a dimension of $30 \times 50 \times 50 \mathrm{~cm}^{3}$, containing 3 artificial cracks of $0.5 \times 5 \mathrm{~cm}^{2}$ at different depths. Regarding crack 2 as the scanning center, the antennas move simultaneously from the right to the left to obtain the frequency response $S_{21}$ for each $1 \mathrm{~cm}$ step, with $X_{\max }=40 \mathrm{~cm}$. The other experimental parameters are given in Table 2 .

The generated B-scan in the time domain is shown in Figure 5(b). From this figure, the reflections from different interfaces are observed: interfacel between the air and the concrete, interface 2 between the concrete 2 and concrete 3 , steel plate of the bottom. Also, the scattering signals from the cracks can be found, as indicated in the figure. However, some unwanted noise is also recorded. It is caused by the heterogeneity of the concrete and the ringing noise between the antennas and the instrument.

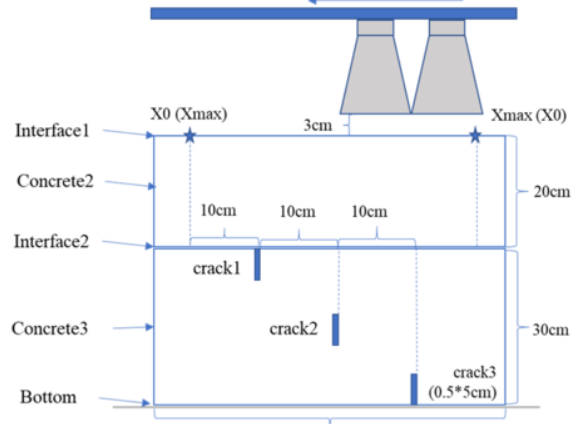

(a)

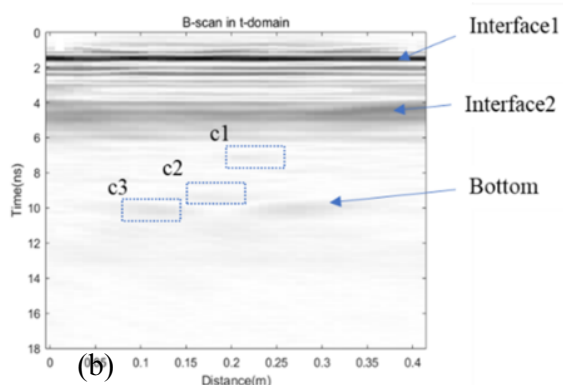

(b)

Figure 5. Experimental setup for cracks of different depths in concrete (a) and its generated B-scan (b)

Table 2. Experimental parameters

\begin{tabular}{rrc}
\hline Component & Parameter & Definition \\
\hline Antennas & Type & Brotex 1-4GHz horn \\
& Tx-Rx distance & $16.5 \mathrm{~cm}$ \\
\multirow{2}{*}{ VNA (N9913A) } & Frequency range & $1-4 \mathrm{GHz}$ \\
& Sampling points & 201 \\
& Required signal & $\mathrm{S}_{21}(x, f)$ \\
Motion controller & Step size & $1 \mathrm{~cm}$ \\
& Scanning distance & $X \mathrm{max}$ \\
\hline
\end{tabular}

\section{Conclusions}

This paper presents a brief review of GPR systems and the state-of-the-art of GPR applications on ballastless railways. The experimental results show that the proposed system can detect all the narrow cracks in the depth up to $50 \mathrm{~cm}$ in the sample. More quantitative non-destructive evaluation of ballastless railways and optimization of the instrumental system will be undertaken in the future. 


\section{Acknowledgment}

This work is a contribution to the key project of the Science \& Technology Department of Sichuan Province (2018GZ0047). The authors would also like to thank the National Natural Science Foundation of China (61701085).

\section{References}

[1] W. Shao, A. Bouzerdoum, S. L. Phung, et al., Automatic classification of ground-penetrating-radar signals for railway-ballast assessment, IEEE Transactions on Geoscience \& Remote Sensing, 10 (2011), 39613972.

[2] K. Ando, M. Sunaga, H. Aoki, O. Haga, Development of slab tracks for hokuriku shinkansen line, Quarterly Report of RTRI, 1 (2001), 35-41.

[3] Xinhuanet, China's high-speed rail will reach 39,000 kilometers by the end of 2020, 5 (2020). http://www.xinhuanet.com/2020-05/19/c 1126004736.htm

[4] C. Esveld. Recently developments in slab track, European Railway Review, 2 (2003), 81-85.

[5] Britpave, Infrastructure group calls for whole life concrete slab track solution, Global Railway Review, 10 (2016).

[6] X. Liu, P. Zhao, F. Dai, Advances in design theories of high-speed railway ballastless tracks, Journal of Modern Transportation, 3 (2011), 154-162.

[7] J. Hugenschmidt, Railway track inspection using GPR, Journal of Applied Geophysics, 2 (2000), 147-155.

[8] I. Al-Qadi, W. Xie, R. Roberts, Optimization of antenna configuration in multiple-frequency ground penetrating radar system for railroad substructure assessment, NDT and E International, 43 (2010), 2028.

[9] X. Xiao, Détermination de Gradients de Teneur en Eau dans les Bétons par Méthodes Électromagnétiques, University of Nantes, France, 2015.

[10] W. W. L. Lai, X. Dérobert, P. Annan, A review of ground penetrating radar application in civil engineering: a 30-year journey from locating and testing to imaging and diagnosis, NDT and E International, 96 (2018), 58-78.

[11] S. Lahouar, and I. Al-Qadi, Automatic detection of multiple pavement layers from GPR data, NDT\& E International, 41 (2008), 69-81.

[12] Y. Zan, Z. Li, G. Su and X. Zhang, An innovative vehicle-mounted GPR technique for fast and efficient monitoring of tunnel lining structural conditions, Case Studies in Nondestructive Testing \& Evaluation, Part A, 6 (2016), 63-69.

[13] Association Française de Génie Civil (AFGC), Concrete Design for A Given Structure Service Life: Durability Management with Regard to Reinforcement Corrosion and Alkali-Silica Reaction, Paris, 2007

[14] G. Villain, Vers Une Évaluation des Indicateurs de Durabilité du Béton pour le Suivi de Ses Dégradations en Laboratoire et sur Ouvrage, Ifsttar, Bouguenais, France, 2012. (in French)

[15] Z. Zeng, X. He, X. Meng and K. Zhu, Experimental study on mechanical characteristics of CRTSIII slab ballastless track under train load, International Conference on Architectural, Civil and Hydraulics Engineering (ICACHE 2015), Guangzhou, China, November, 2015.

[16] P. E. Gautier, Slab track: Review of existing systems and optimization potentials including very high speed, Construction and Building Materials, 92 (2015), 9-15.

[17] H. Wang, A. Che, S. Feng, et al., Full waveform inversion applied in defect investigation for ballastless undertrack structure of high-speed railway, Tunnelling \& Underground Space Technology, 51 (2016), 202-211.

[18] C. Colla, M. Krause, Ch, Maierhofer et al., Combination of NDT techniques for site investigation of nonballasted railway tracks, NDT \& E International, 35 (2002), 95-105.

[19] A. Gardei, K. Mittag, H. Wiggenhauser, B. Riple, M. Jovanovic: Inspection of concrete-embedded tracks process development for the quality assurance of concrete-embedded tracks using non-destructive testing methods. Non-destructive Testing in Civil Engineering, 2003.

[20] J. Li, Ground penetrating radar detection of voids and gaps at the bottom of support plate of high-speed railway ballastless track, Road and Bridge Technology, 18 (2015), 224-225. (in Chinese)

[21] S. Fontul, E. Fortunato, F. De Chiara et al., Railways track characterization using ground penetrating radar, Procedia Engineering, 143 (2016), 1193-1200.

[22] L. Pajewski, S. Fontul, M. Solla, Chapter 10 - Ground-penetrating radar for the evaluation and monitoring of transport infrastructures, Innovation in Near-Surface Geophysics, Elsevier, (2019), 341-398. 
[23] A. Kalogeropoulos, J. van der Kruk, J. Hugenschmidt, et al., Full-waveform GPR inversion to assess chloride gradients in concrete, NDT \& E International, 57 (2013), 74-84.

[24] X. Xiao, B. Guan, A. Ihamouten, et al., Monitoring water transfers in limestone building materials with water retention curve and ground penetrating radar: a comparative study, NDT \& E International, 100 (2018),31-39.

[25] S. S. Todkar, C. Le Bastarda, V. Baltazart et al., Performance assessment of SVM-based classification techniques for the detection of artificial debondings within pavement structures from stepped-frequency A-scan radar data, NDT \& E International, 107 (2019), 102128.

[26] X. Dérobert, C. Fauchard, Ph. Côte et al., Step-frequency radar applied on thin road layers, Journal of Applied Geophysics, 47 (2001), 317-325.

[27] Z. Khakiev, V. Shapovalov, A. Kruglikov, V. Yavna, GPR determination of physical parameters of railway structural layers, Journal of Applied Geophysics, 106 (2014), 139-145. 